\title{
ROLE OF URODYNAMICS IN MANAGEMENT OF PATIENTS WITH PELVIC ORGAN PROLAPSE
}

Karnika Tiwari ${ }^{1}$, Veena Acharya ${ }^{2}$, Babit Kumar ${ }^{3}$, Urvashi Sharma ${ }^{4}$, Prabjot Singh Hans ${ }^{5}$

\section{HOW TO CITE THIS ARTICLE:}

Karnika Tiwari, Veena Acharya, Babit Kumar, Urvashi Sharma, Prabjot Singh Hans "Role of Urodynamicsin Management of Patients with Pelvic Organ Prolapse". Journal of Evolution of Medical and Dental Sciences 2015; Vol. 4, Issue 47, June 11; Page: 8209-8215, DOI: 10.14260/jemds/2015/1188

ABSTRACT: Utero-vaginal prolapse (UV) is a common condition affecting millions of women worldwide, and a major cause of gynecological surgery. Although it is not life threatening but, it can have a severe impact on quality of life. Prolapse is a protrusion of a pelvic organs beyond its normal anatomical confines and it represents the failure of fibromuscular support to maintain normal position. Urodynamic Study (UDS) is the dynamic study of the transport, storage and evacuation of urine. The ultimate goal of urodynamics is to aid in the correct diagnosis of urinary incontinence based on pathophysiology. Urodynamic studies assess both the filling storage phase and the voiding phase of the bladder and urethral function. AIM: of this study is to assess the role of urodynamic measures in pelvic organ prolapse (POP) patients for identifying the urinary problems concomitant with prolapse for proper management. The use of urodynamic tests are for diagnosis, prognosis, guidance of clinical management and decision for type of surgery that results in improvement of patient outcomes with various urological conditions.

KEYWORDS: With Pelvic Organ Prolapse (POP) Urodynamic Study Urinary Incontinence.

INTRODUCTION: Utero-vaginal prolapse (UV) is a common condition affecting millions of women worldwide, and a major cause of gynecological surgery. Although it is not life threatening but, it can have a severe impact on quality of life.

Prolapse is a protrusion of a pelvic organs beyond its normal anatomical confines and it represents the failure of fibromuscular support to maintain normal position.(1) Two third of affected women have concominent cystocele and/or rectocele. Cystocele is primarily the result of weakened pubocervical fascia.(2)

Women with UV prolapse may present with a wide range of lower urinary tract symptoms. The prolapse may mechanically obstruct the urethra, leading to bladder outlet obstruction, impede voiding and mask urinary incontinence. ${ }^{(3)}$

The pathophysiology of Stress Urinary Incontinence (SUI) and Pelvic Organ Prolapse (POP) are related and can be considered multifactorial. These factors may be divided into intrinsic (Genetic, age, postmenopausal status, ethinicity) and extrinsic components (Parity, history of previous delivery, co-morbidities and patient's occupation). Overall, irrespective of the inciting factor, the end result is the same: an anatomical defect in the endopelvicfascial layer leads to prolapse. The clinical factors involved in prolapse are damage of the soft tissues sustained during pregnancy and weakening of pelvic floor tissue during menopause. ${ }^{(4)}$

Prolapse and urinary incontinence often occur concomitantly. Anterior vaginal wall prolapse may present as stress incontinence. A large cystocele may cause uretheral kinking and overflow incontinence. Uterine descent can cause lower back and sacral pain. Enterocele may cause only vague symptoms of vaginal discomfort. A rectocele can lead to incomplete evacuation of stool. Stress incontinence is described as the involuntary leakage of urine when the intravesical pressure exceeds 


\section{REVIEW ARTICLE}

the maximum uretheral pressure in the absence of detrusor activity. Its main causal factor is the descent of bladder base and the urethera and loss of the angle normally seen between them in UteroVaginal prolapse patients. ${ }^{(5)}$

Urge urinary incontinence is the complaint of involuntary leakage accompanied by or immediately preceded by urgency. Whereas, mixed urinary incontinence is the compliant of involuntary leakage associated with urgency and also with effort, exertion, sneezing and coughing.

Urodynamic studies have advantage to know the type of urinary problems associated with utero-Vaginal prolapse (POP).

The Aim of The Surgery: is to restore urinary function and any concomitant urinary incontinence associated with prolapse. Before Surgery, a thorough history and physical examination are the most important means of assessment of the patients presenting with the symptoms of urinary problems with prolapse.(6):

- Stress incontinence.

- Urge incontinence.

- Frequency of micturition.

- Difficulty in initiation of micturition.

- Sensation of incomplete emptying of the bladder.

- Nocturia.

- Retention of urine.

Urodynamic Study (UDS) is the dynamic study of the transport, storage and evacuation of urine. The ultimate goal of urodynamics is to aid in the correct diagnosis of urinary incontinence based on pathophysiology. Urodynamic studies assess both the filling storage phase and the voiding phase of the bladder and urethral function.

AIM: Aim of this study is to assess the role of urodynamic measures in pelvic organ prolapse (POP) patients for identifying the urinary problems concomitant with prolapse for proper management. The use of urodynamic testsare for diagnosis, prognosis, guidance of clinical management and decision for type of surgery that results in improvement of patient outcomes with various urological conditions. The urodynamic studies are useful in U-V prolapse patients for management and it would help to decide the specific type of surgery required for management of patients.

METHOD: The present study was carried out on 50 patients of pelvic organ prolapse patients with complaints of Pelvic Organ Prolapse (POP) visiting the gynaecology OPD with or without urinary complaints.

Detailed clinical history of the patients, including past and present complaints, clinical examination, laboratory assessment, Urodynamic studies and further management was done and correlated.

URODYNAMIC STUDIES: The urodynamic study carried out in all the 50 patients with pelvic organ prolapse were as follow:

- Uroflowmetry.

- Cystometry.

- $\quad$ Leak Point Pressure Profile. 
The study was carried out on the Urodynamic machine consisting of a uroflow transducer, a pressure transducer stand and an instrument showing different panels:

1. Mictiometer and uroflow transducer measures the urinary flow rates. The patients voids into the funnel of the uroflow transducer. The parameters recorded were:
a) Flow (ml/sec.)
b) Volume $(\mathrm{ml})$
c) Mean flow (ml/sec.)
d) Voiding time (sec.)

2. The manometer measures the following:

a) Abdominal pressure is recorded from rectum.

b) Intravesical pressure-measured by putting a catheter in the bladder either suprapubically or transuretherally.

c) Detrusor pressure is the intravesical pressure minus the intra-abdominal pressure.

d) A water pump is used to infuse water into the bladder.

\section{RESULTS:}

\begin{tabular}{|c|c|c|}
\hline Age & Number of Patients & Percentage \\
\hline $31-40$ & 02 & $04 \%$ \\
\hline $41-50$ & 12 & $24 \%$ \\
\hline $51-60$ & 28 & $56 \%$ \\
\hline$>60$ & 08 & $16 \%$ \\
\hline Total (N) & $\mathbf{5 0}$ & $\mathbf{1 0 0 \%}$ \\
\hline \multicolumn{3}{|c|}{ Table 1: Age Distribution } \\
\hline
\end{tabular}

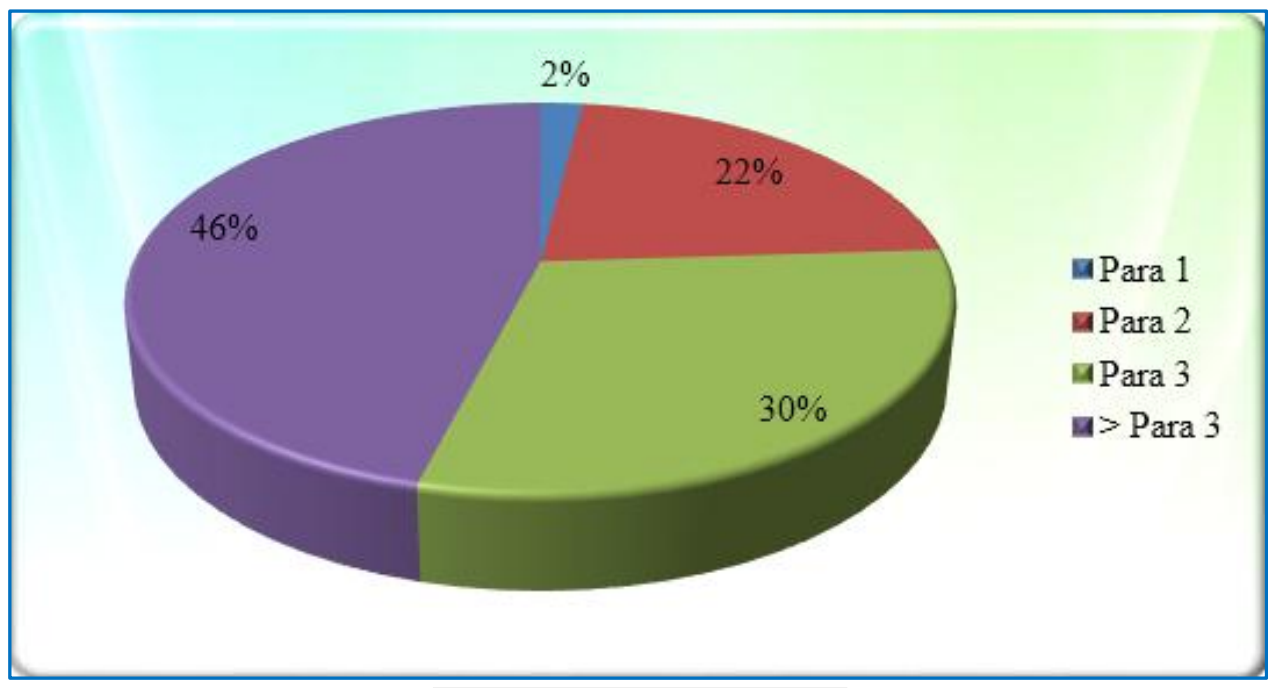

Parity Distribution 


\begin{tabular}{|c|c|c|c|}
\hline & Medical History & Number of Patients & Percentage \\
\hline a) & Chronic Cough & 20 & $40 \%$ \\
\hline b) & Hypertension & 19 & $38 \%$ \\
\hline c) & Diabetes & 14 & $28 \%$ \\
\hline d) & Asthma & 05 & $10 \%$ \\
\hline e) & Epilepsy & 01 & $02 \%$ \\
\hline f) & Tuberculosis & 03 & $06 \%$ \\
\hline g) & HIV & 00 & $00 \%$ \\
\hline h) & Others & 04 & $08 \%$ \\
\hline \multicolumn{4}{|c|}{ Table 2: Correlation of Pelvic Organ } \\
\hline \multicolumn{3}{|c|}{ Prolapse According to Medical History } \\
\hline
\end{tabular}

\begin{tabular}{|c|c|c|c|}
\hline & Occupation & Number of patients & Percentage \\
\hline \multirow{2}{*}{1.} & Manual Labour (n=31) & & \\
& a) Farmer (working in field) & 19 & $38 \%$ \\
& b) Working in factories & 12 & $24 \%$ \\
\hline 2. & Housewife & 13 & $26 \%$ \\
\hline 3. & Office Staff & 06 & $12 \%$ \\
\hline & Total (N) & $\mathbf{5 0}$ & $\mathbf{1 0 0 \%}$ \\
\hline
\end{tabular}

Table 3: Occupation Distribution

\begin{tabular}{|l|c|c|c|}
\hline & Pop-Q Classification & Number of Patients & Percentage \\
\hline a) & Stage 0 & 0 & $0 \%$ \\
\hline b) & Stage 1 & 4 & $8 \%$ \\
\hline c) & Stage 2 & 6 & $12 \%$ \\
\hline d) & Stage 3 & 30 & $60 \%$ \\
\hline e) & Stage 4 & 10 & $20 \%$ \\
\hline
\end{tabular}

Table 4: Distribution According to Pop-Q Staging of Prolapse

$\mathrm{N}=50$

\begin{tabular}{|c|c|c|c|c|c|}
\hline Clinical diagnosis & \begin{tabular}{|c|} 
Stress \\
incontinence
\end{tabular} & $\begin{array}{c}\text { Detrusor } \\
\text { instability }\end{array}$ & Obstruction & Neurogenic & $\mathbf{N} / \mathbf{A}$ \\
\hline $\begin{array}{l}\text { Stress incontinence } \\
\qquad(\mathrm{n}=18)\end{array}$ & $\begin{array}{c}9 \\
(50 \%)\end{array}$ & $\begin{array}{c}5 \\
(27.77 \%) \\
\end{array}$ & $\begin{array}{c}1 \\
(5.55 \%)\end{array}$ & $\begin{array}{c}1 \\
(5.55 \%)\end{array}$ & $\begin{array}{c}2 \\
(11.11 \%)\end{array}$ \\
\hline $\begin{array}{l}\text { Urge incontinence } \\
\qquad(\mathrm{n}=22)\end{array}$ & $\begin{array}{c}2 \\
(9.09 \%)\end{array}$ & $\begin{array}{c}12 \\
(54.54 \%)\end{array}$ & $\begin{array}{c}1 \\
(4.54 \%)\end{array}$ & $\begin{array}{c}3 \\
(13.63 \%)\end{array}$ & $\begin{array}{c}4 \\
(18.18 \%)\end{array}$ \\
\hline $\begin{array}{l}\text { Mixed symptoms } \\
(\mathrm{n}=10)\end{array}$ & $\begin{array}{c}2 \\
(50 \%)\end{array}$ & $\begin{array}{c}1 \\
(10 \%)\end{array}$ & $\begin{array}{c}4 \\
(40 \%)\end{array}$ & $\begin{array}{c}1 \\
(10 \%)\end{array}$ & $\begin{array}{c}2 \\
(20 \%) \\
\end{array}$ \\
\hline $\begin{array}{l}\text { TOTAL } \\
(\mathrm{N}=50)\end{array}$ & $\begin{array}{c}13 \\
(26 \%)\end{array}$ & $\begin{array}{c}18 \\
(36 \%)\end{array}$ & $\begin{array}{c}6 \\
(12 \%)\end{array}$ & $\begin{array}{c}5 \\
(10 \%)\end{array}$ & $\begin{array}{c}8 \\
(16 \%)\end{array}$ \\
\hline
\end{tabular}


REVIEW ARTICLE

URODYNAMIC TEST RESULTS PREOPERATIVE CYSTOMETRIC PATAMETERS:

\begin{tabular}{|c|c|c|}
\hline & No of Patients & Percentage \\
\hline Present & 13 & $26 \%$ \\
\hline Absent & 37 & $74 \%$ \\
\hline \multicolumn{2}{|c|}{ Table 6: Leak Point (On Cough) on cystometry } \\
\hline
\end{tabular}

$$
\mathrm{N}=50
$$

\begin{tabular}{|c|c|c|}
\hline $\begin{array}{c}\text { Stage 4 of prolapse } \\
\text { (POP-Q) }\end{array}$ & $\begin{array}{c}\text { Mean value of Qmax } \\
\text { (ml/sec) }\end{array}$ & $\begin{array}{c}\text { Mean volume voided } \\
\text { (ml) }\end{array}$ \\
\hline Stage 1 & 23.95 & 443 \\
\hline Stage 2 & 17.35 & 449 \\
\hline Stage 3 & 10.72 & 348 \\
\hline Stage 4 & 5.13 & 123 \\
\hline
\end{tabular}

Table 7: Uroflowmetry Values Correlation with Stage of Prolapse

$$
\mathrm{N}=50
$$

\begin{tabular}{|c|c|c|c|c|c|c|}
\hline \multirow{2}{*}{$\begin{array}{l}\text { Urodynamic } \\
\text { Results }\end{array}$} & \multicolumn{2}{|c|}{$\begin{array}{c}\text { Uroflowmetric } \\
\text { Parameters (Mean) }\end{array}$} & \multicolumn{4}{|c|}{$\begin{array}{l}\text { Cystometry } \\
\text { (Mean) }\end{array}$} \\
\hline & $\begin{array}{c}\text { Qmax } \\
\text { (ml/sec) }\end{array}$ & $\begin{array}{l}\text { VV } \\
(\mathrm{ml})\end{array}$ & FS & BC & Pves FS & Pves BC \\
\hline Stress Incontinence $(n=13)$ & 12.82 & 257.05 & 157 & 363 & 13.4 & 21.2 \\
\hline Detrusor Instability $(n=18)$ & 11.37 & 247.06 & 131.66 & 293 & 21 & 28.74 \\
\hline Obstruction $(n=6)$ & 3.82 & 193.4 & 152 & 455 & 15.4 & 22 \\
\hline Neurogenic $(n=5)$ & 8.18 & 478.25 & 312 & 518 & 25.6 & 32 \\
\hline No Abnormality $(\mathrm{n}=8)$ & 14.37 & 388.87 & 174 & 323 & 14.8 & 28.8 \\
\hline
\end{tabular}

\begin{tabular}{|c|l|c|c|c|}
\hline \multicolumn{3}{|c|}{ TYPE OF SURGERY } & 4 & No other Treatment \\
\hline 1 & Vaginal Hysterectomy +Anterior Repair & 5 & 1 & Medical Rx of UTI \\
\hline 2 & Vaginal Hysterectomy + Anterior Repair + TOT & 05 (Associated Stress Incontinence) \\
\hline 3 & Vaginal Hysterectomy + Anterior Repair + PFR + TOT & 08 & (Associated stress Incontinence) \\
\hline 4 & Vaginal Hysterectomy +Anterior repair + PFR & 8 & 5 & No other Treatment \\
\cline { 3 - 5 } & Vaginal Hysterectomy + PFR + Medical Treatment & 3 & Medical Rx for UTI \\
\hline 6 & Vaginal Hysterectomy + PFR + Neurophysician counselling & 6 (Associated Neurogenic Problems) \\
\hline
\end{tabular}


DISCUSSION: In our study, we have taken 50 patients of Pelvic Organ prolapse, all were subjected to urodynamic study to know the preoperatively Urinary Problems associated with prolapse.

In our group, mean age of the patients was 54.34 yrs. \pm 8.952 Standard Deviation. Mean Parity was P3. Most of the patient belonging to Lower socioeconomic group and they are illiterate coming from rural area.

All patients were presenting in gynaecology OPD with the complaint of something coming out of vagina with associated complaints of stress incontinence in 36\%, Urge Incontinence in $44 \%$ and mixed complaints-Dysuria, difficulty in voiding, Dribbling of urine, and others in $20 \%$ and $14 \%$ presenting with the burning micturition.

These patients also have significant medical history-Hypertension 38\%, Diabetes 28\%, Asthma 10\%, chronic cough 40\%and constipation 24\%.

Past history showed that $30 \%$ had previous surgery, $4 \%$ had history of trauma and spinal cord injury and $6 \%$ had neurological problems.

On clinical examination, according to POP-Q Classification, $60 \%$ had stage 3 and $20 \%$ had stage 4. Mean BMI of the patients was 22.5.

In my study group of 50 patients with Pelvic Organ Prolapse, all patients were subjected to urodynamic studies. After urodynamic studies, 18 patients $(36 \%)$ who clinically presented with complaints of stress incontinence, $9(50 \%)$ patients were demonstrated on UDS as stress incontinence, $5(27.77 \%)$ patients as detrusor instability, $1(5.5 \%)$ patient as obstruction and $1(5.5 \%)$ patient as neurogenic. $2(11.11 \%)$ patients showed no abnormality.

Out of 22(44\%) patients who clinically presented with complaints of urge incontinence, after undergoing Urodynamic studies, 2(9.09\%) had stress incontinence, 12(54.54\%) had detrusor instability, 1(4.54\%) had obstruction and 3(13.63\%) had neurogenic cause. 4(18.18\%) patients showed no abnormality.

Out of $10(20 \%)$ patients clinically presenting with mixed symptoms, after undergoing urodynamic studies, $2(50 \%)$ had stress incontinence, $1(10 \%)$ had urge incontinence, 4(40\%) had obstruction and $1(10 \%)$ had neurogenic cause. 2 patients (20\%) showed no abnormalities.

Out of total 50 patients taken in the study group, urodynamic study confirmed 13 patients (26\%) having stress incontinence, 18 patients (36\%) having urge incontinence (detrusor instability), 6 patients $(12 \%)$ having obstruction and 5 patients $(10 \%)$ having neurogenic cause. 8 patients $(16 \%)$ showed no abnormalities. This shows that Urodynamic test is useful in identifying the cause of incontinence and other urinary problems associated with prolapse and hence, helps in following the appropriate treatment required for the same.

To conclude our results of 50 patients with POP the available evidence suggested on urodynamic evaluations that find out the exact number of the patients of Stress Incontinence 13, Detrusor Instabilities-18, Obstructive pathology 6, Neurogenic-5 and No abnormalities was detected in 9 patients.

In our study group, 13 patients of POP who were diagnosed as Stress Incontinence, underwent Vaginal Hysterectomy with TOT. 18 Patients who were diagnosed as detrusor Instabilities in POP patients, were subjected to medical treatment-Anti Cholinergic and Anti Muscarinics for 3 months before surgery and continue after the vaginal Hysterectomy with anterior and Posterior Colpoperineoraphy. 6 patients Of Stage 4 POP-Q Classification (Procedentia) were diagnosed as Bladder Outlet Obstruction (BOO). 5 Patients diagnosed as neurogenic Problems with POP were 
properly counseled and referred to Neuro Physician before surgery. 8 Patients, no LUTS was diagnosed on UDS underwent simple Vaginal Hysterectomy with colpoperineoraphy.

To conclude from our study that the urodynamic studies are very useful in U-V prolapse patients, preoperatively in women undergoing the prolapse surgery. It helps to identify the patients with stress incontinence, Detrusor Instabilities, Bladder Outlet Obstruction, Neurogenic Bladder for proper management and to decide preoperatively the type of surgery.

\section{REFERENCES:}

1. Swift SE, Tate SB, Nicholas J. Correlation of symptoms with degree of pelvic organ support in a general population of women: What is pelvic organ prolapse? Am J Obstet Gynecol 2003; 189: 372-9.

2. Olsen AL, Smith VG, Bergstrom JO, Colling JC, Clark AL. Epidemiology of surgically managed pelvic organ prolapse and urinary incontinence. Obstet Gynecol 1997; 89: 501-6.

3. Swift SE. The distribution of pelvic organ support in a population of female subjects seen for routine gynecologic health care. Am J Obstet Gynecol 2000; 183: 277-85.

4. Indian J Urol. 2007 Apr-Jun; 23(2): 135-141. Pelvic organ prolapse and stress urinary incontinence: A review of etiological factors Payal D. Patel, Kaytan V. Amrute, * and Gopal H. Badlani

5. Marinkovic SP, Stanton SL. Incontinence and voiding difficulties associated with prolapse. J Urol. 2004 Mar; 171 (3):1021-8.

6. Abrams P et al: Neurourol Urodyn. 2010; 29(1):213-40. 4th International Consultation on Incontinence Recommendations of the International Scientific Committee: Evaluation and treatment of urinary incontinence, pelvic organ prolapsed and fecal incontinence. Members of Committees; Fourth International Consultation on Incontinence.

\section{AUTHORS:}

1. Karnika Tiwari

2. Veena Acharya

3. Babit Kumar

4. Urvashi Sharma

5. Prabjot Singh Hans

\section{PARTICULARS OF CONTRIBUTORS:}

1. Resident, Department of Obstetrics and Gynaecology, Mahatma Gandhi Medical College and Hospital, Jaipur.

2. Professor, Department of Obstetrics and Gynaecology, Mahatma Gandhi Medical College and Hospital, Jaipur.

3. Senior Resident, Department of Radiology, Mahatma Gandhi Medical College and Hospital, Jaipur.

FINANCIAL OR OTHER COMPETING INTERESTS: None
4. Senior Resident, Department of Obstetrics and Gynaecology, Mahatma Gandhi Medical College and Hospital, Jaipur.

5. Resident, Department of Obstetrics and Gynaecology, Mahatma Gandhi Medical College and Hospital, Jaipur.

\section{NAME ADDRESS EMAIL ID OF THE CORRESPONDING AUTHOR:}

Karnika Tiwari,

Department of Obstetrics and Gynaecology, Mahatma Gandhi Medical College and Hospital, Jaipur.

E-mail: drkarnika_angel@yahoo.com

Date of Submission: 10/04/2015.

Date of Peer Review: 11/04/2015.

Date of Acceptance: 04/06/2015.

Date of Publishing: 10/06/2015. 